\title{
A Comprehensive Management Model Based on Modularization Thought
}

\author{
Ting Ting Tan ${ }^{* 1, a}$,Chong Zhao ${ }^{1, b}$, Li Hong Du ${ }^{1, c}$,Jing Zhao ${ }^{1, d}$ \\ ${ }^{1}$ School of Management Xi'an High-Tech Research Institute Baqiao District, Xi'an City
}

\begin{abstract}
The general modular management theory takes organizational structure, work flow and product design and production as the core. In practice, it only pays attention to a certain aspect of modularization, and does not establish a comprehensive and unified modular management system. In this context, this article, guided by modular thinking, constructs a comprehensive management model based on modular thinking, and elaborates on the basic management structure of the modular management system. Meanwhile, this paper discusses the practical requirements of promoting modular management mode from the perspective of system, stability and moderation. It is hoped that this research can promote the theoretical innovation of comprehensive modular management and also provide a reference for the innovative practice of enterprise business models.
\end{abstract}

\section{Introduction}

Smith emphasized specialization and social division of labor in the book The Wealth of Nations. The production of pins in the masterpiece is regarded as a case of modular production and processing [1]. The modularization idea was developed when Simon put forward the concept of near decomposability on the basis of near decomposable system [2]. Simon believes that complex systems have a hierarchical structure, and most of them have near decomposability, a complex system is composed of many interactive subsystems, and the interaction within the subsystems is stronger than the interaction between the subsystems. Based on this, the interaction within the subsystem is decomposed from the interaction between the subsystems. This decomposition can help people understand and analyze complex systems, but Simon's point of view has not attracted people's attention. In 1997, Baldwin and Clark published an article in Harvard Business Review to formally put forward the concept of modularity. By studying the management methods adopted by IBM in the R\&D of System/360, they believed that modularity is based on overall efficiency and emphasized the decomposition and combination of modularity [3].

With the continuous development of mass customization and the increasing individual needs of consumers, modular theory has attracted increasing attention from academic circles and entrepreneurs. The majority of scholars have enriched the research of management theory from different entry points from the perspective of modularization. Modularization has an important impact on products, business processes, and organizational structures. Among them, product design has been studied most, including product design, innovation, and production. Antonio pointed out that product modularity means that products have high product modularity (i.e. modular product design), and product systems have independent modular characteristics [4]. Modular design can reduce complexity, facilitate independent development and effective combination to form new products, and accelerate product innovation [5]. Product modularity can easily assemble different components to create the diversity of the final product [6].

However, a comprehensive modular management plan has not yet been constructed. Based on this, this article first sorts out the concept of modular management. Second, building a modular management plan around corporate management activities. Finally, putting forward the implementation requirements of the modular management program. Therefore, the article consists of the following four parts, the first part is the concept of modular management; the second part is the modular management plan; the third part is the implementation requirements; the last part is the summary.

\section{The concept of modular management}

Modularization has a wide range of applications, and the research focus in different fields is very different, but the academic community has not reached a consensus on the definition of modular management. Baldwin and Clark believe that modularity is a process in which independently designed units act as subsystems through certain rules [3]. Masahiko Aoki and Haruhiko Ando of Japan conducted a more in-depth study of modularization. They believe that modularization is an independently designed and semi-autonomous unit that follows a certain

\footnotetext{
a*Email:1150783390@qq.com ㅎEmail:124585241@qq.com ㄷEmail: sunflowerv@163.com demail:48789456@126.com
} 
rule of decomposition or combination process[7]. Decomposition and combination are defined as the decomposition of modules and the combination of modules. The above research shows that modularization is the process of decomposing the whole and realizing the overall function through the synergy between the decomposed units. The essence is to deal with the relationship between decomposition and combination, specialization and integration.

Management is the process of conducting management activities on management objects (business, organization, resources, and systems) in a specific environment. Modular management does not simply superimpose the two concepts, but applies the modular idea to management. Based on the above research content, modular management includes the following two meanings: specialized decomposition and integrated integration.

\section{A. Specialized decomposition}

It refers to the design of management objects as independent subsystems.

\section{$B$. Integrated integration}

It refers to the integration of independently designed subsystems into a management system that accomplishes management goals.

\section{Modular Management Program}

This article focuses on the four major elements of the management target business, organization, resources, and system, and builds a modular management system from multiple dimensions such as theory, method, and business practice. The program includes two levels and seven parts ( Fig. 1).

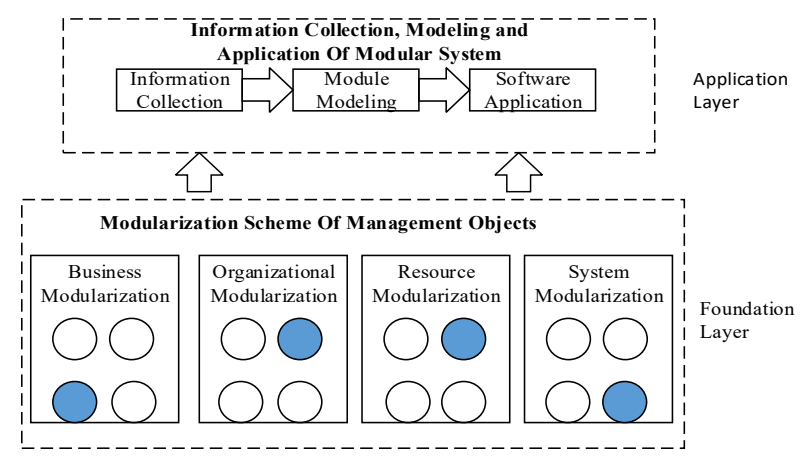

Fig1. Modular Management System.

The foundation layer is the basic of the modular management system, mainly starting from the four elements of the management objects, and basically covering the entire content of the management activities, so as to achieve all-round management. The basic layer includes four aspects: organizational modularization, business modularization, resource modularization, and system modularization.

The application layer focuses on the help generated by computer technology, and the basic layer focuses on the efficient decomposition and combination of management activities with the help of modular ideas, so as to realize the management model innovation and mechanism innovation of enterprise management activities. Therefore, this article focuses on the basic layer, and introduces the enterprise modular management plan from the four aspects of business, organization, resources, and system.

\subsection{Business modularization}

It is necessary for companies to take customer needs and satisfaction as the ultimate goal, fundamentally rethink and redesign existing business processes, to ensure efficient and high-quality business development, ensure rapid response to consumers and the market, and improve the core competitiveness of enterprises.

For enterprises, business includes two parts: external business and internal business. The level of business directly affects the collaborative development of the enterprise and customer satisfaction. Therefore, the quality and efficiency of the business play a vital role in the growth of the enterprise and the quality of the final product and service. From the perspective of modularity, business modularity can strengthen the business capabilities of enterprises and improve their own management efficiency, which is very important for enterprises to improve their management level.

\subsubsection{Modularization can improve business efficiency.}

Each process module of an enterprise activity has a set of functions, which form the basis for selecting modules to complete a given task. Erlicher and Massone pointed out that in order to meet changes in demand, you can choose to activate or deactivate business modules [7]. Through modular means, with the goal of improving the efficiency of business processes, the company' $\mathrm{s}$ business is decomposed and packaged into mutually independent modules, and related modules could be tuned and modified according to task requirements. Enterprises can increase the utilization rate of business processes and reduce the waste in business process.

\subsubsection{Modularization can meet the needs of flexible business development.}

With the continuous enhancement of the dynamic market environment and the diversified development of customer needs, companies must adapt to the dynamic changes of market demand and establish flexible business processes. The "plug-and-play" feature of business modularity realizes the requirement of combining business according to demand, thereby realizing the diversification of business process functions, making the enterprise more responsive, able to meet customer needs and seizing market opportunities to a greater extent.

\subsection{Organizational modularization}

It is necessary to decompose the integrated organization into modules based on the division of business modules, establish an enterprise internal transaction system, introduce market competition mechanisms, and improve the enterprise's ability to prevent risks.

Henderson and Clark pointed out that while maintaining the existing structure, redistributing the 
relative importance of individual functions, this is organizational innovation [3]. Organizational modularization requires enterprises to decompose the integrated organization into modules based on the characteristics of business modules, clarify the affiliation between modules, flatten the organizational structure, reduce management levels, and realize rationalization of the internal structure of the enterprise and maximize efficiency.

\subsubsection{Modularity contributes to the smooth and efficient communication within the enterprise.}

Enterprises obtain diversified economic benefits by optimizing the combination of modules of different organizational units, and at the same time greatly reduce the management complexity caused by differences.

On the one hand, organizational modularity is conducive to reducing management levels and closer relationships between modules, thereby accelerating the flow of information

On the other hand, each organizational module can more clearly define its own rights and responsibilities, making the correlation between modules clearer and breaking the traditional organizational structure under the barriers that block inter-departmental communication, it can strengthen the collaboration between organizational modules.

\subsubsection{Organizational modularization can improve the company's ability to respond to environmental and market dynamics.}

Modular management can improve the company's ability to respond to environmental and market dynamics. Business modularity makes the division of labor more clear, and the clear division of labor leads to the disintegration of large vertically integrated companies [8] and the formation of a modular organizational structure. Each organizational module is an independent unit with autonomy and independence.

Therefore, compared with the traditional loose organizational structure, organizational modularity can flexibly respond to changes in the external environment. Third, organizational modular management can reduce management costs. The adjustment of the organizational structure level brings certain personnel changes, and the reduction of the organizational level reduces the management level and reduces the cost of enterprise management.

\subsection{Resource modularization}

It is necessary to rationally allocate corporate resources according to the breakdown structure of business modules and organizational modules to achieve effective allocation of material, financial, and information resources, reduce resource consumption, and improve business benefits.

Resource modularization requires companies to cooperate and interact with suppliers based on their own resource conditions. In the management process of facility and equipment management, financial resource management, supplier and partner resource management, etc., through the use of modular methods to achieve efficient resource allocation. Give full play to the auxiliary role of resources in enterprise management, improve resource operation efficiency, and reduce resource idle rate at the same time.

\subsubsection{Resource modularization helps improve the enterprise resource management system.}

The enterprise resource allocation management system involves diversification of content. Traditional resource allocation plans tend to lack execution, and the efficiency and quality of resource allocation cannot be guaranteed. Through modular management methods, companies can divide resources into resource modules with weak links by combing the resource management value chain, and combine modules arbitrarily in the actual management process to achieve efficient resource allocation and give full play to the complementary effects of superior resources.

\subsubsection{Modularization is a necessary technical means for upgrading resource allocation.}

Firstly, compared with the traditional loose resource management mode, the miniaturization of resource modules reduces management costs and makes management more convenient and efficient. Secondly, it can improve material resources, facilities, equipment, and information. Liquidity can realize the free combination of resources by splitting and merging modules, providing more choices for different task requirements.

\subsection{System modularization}

It is necessary to create a system that is compatible with the development of the enterprise, and to provide institutional guarantees for the three major modules of business, organization, and resources, to promote the healthy and sustainable development of the enterprise.

System modularization requires the division of system modules according to the company's rules and regulations and the responsibility system according to the strong and weak relationships between systems. In the process of providing products or services to customers, the free combination of system modules is used to anchor organizational mission objectives and highlight the system structure. The characteristics that match the organization, business, and resources enable the normal operation of the enterprise.

\subsubsection{Modularization of the system facilitates the effective development of management activities.}

System is a tool for enterprises to implement business, organization, and resource management, and is the basis for implementing management activities. In the process of business, organization, and resource modularization, different modules use supporting system modules to 
enable each unit module to self-manage, reducing management complexity and saving management resources.

\subsubsection{System modularization helps employees clarify their rights and responsibilities.}

The modular management model means that different modules have different characteristics. According to the business content, organizational level and resource allocation of each module, the system modules are established in a targeted manner, so that each module can clarify its own responsibilities, rights, and interest. Only under the conditions of consistent power and responsibility and clear division of labor can the modules work together efficiently.

\section{Implementation requirements}

Modularization provide researchers with broader application prospects, but they still face many requirements in the implementation of modularization management in enterprises. If these requirements cannot be met, carrying out comprehensive modular management is a castle in the sky. From the perspective of management implementation, this section analyzes and elaborates on the following three requirements when carrying out comprehensive modular management.

\subsection{Set up the overall view and use systematic thinking to carry out modular adjustment.}

Analyze the operation process of the enterprise from a holistic perspective, reduce unnecessary intermediate links, package elements with similar characteristics and strong correlations into modules, and coordinate the relationship between professional decomposition and integration. From the perspective of the enterprise management system, break the inherent vertical division of labor, highlight the horizontal connections between modules, and give play to the advantages of specialized division of labor.

\subsection{Maintain the stability of the company.}

Enterprise transformation is not accomplished overnight. It must be planned in advance, carefully organized, carefully deployed, and steadily advanced. It must be fully clarified that the transformed enterprise can realize the free integration and disassembly of unit modules, strengthen the circulation of people, finances, materials, and information, and improve the enterprise's ability to resist risks before adjusting the management objects.

\subsection{To ensure the moderation of the module}

The function of the module is single, the degree of coupling between the modules is low, and the connection between the modules is less. While it does not mean that the smaller the module, the better. Fully consider the mission needs of the enterprise, combine the characteristics of the elements, and explore the best method of module division with the promotion of comprehensive competitiveness as the traction.

\section{CONCLUSION}

Of course, the support system required for modular management is far more than the above. In any case, however, business modularization, organizational modularization, resource modularization and system modularization cannot be ignored.

This paper constructs a comprehensive management model based on modular, modular thinking for the lead, elaborated on the base layer management structure of modular management systems. Meanwhile, this paper discusses the practical requirements of promoting modular management mode from the perspective of system, stability and moderation. It is hoped that this research can promote the theoretical innovation of comprehensive modular management and also provide a reference for the innovative practice of enterprise business models.

\section{References}

1. Adam. Smith. The Wealth of Nations. Bantam Books. 2003. pp. 10-19.

2. Herbert, A. Simon, The Architecture of Complexity. Proceedings of the American Philosophical, vol. 106, 1962, pp. 46-482.

3. Baldwin, Carliss Y., and Clark, Kim B., Managing in an Age of Modularity. Harvard Business Review, vol. 75, 1997, pp. 84- 93.

4. Antonio K. W. Lau, Richard C. M. Yam, and Esther Tang. The Impact of Product Modularity on New Product Performance: Mediation by Product Innovativeness. Product Development \& Management Association, vol. 28, 2011, pp. 270-284.

5. Ethiraj, S. K., and Levinthal. D, Modularity and innovation in complex systemds. Management Science, vol. 50, 2004, pp. 159-73.

6. Karl Ulrich. The role of product architecture in the manufacturing firms. Research Policy, vol. 24, 1995, pp. 419-441.

7. Masahiko Aoki and Takizawa. H, Incentives and Option Value in the Silicon-Valley Tourament Game. RIETI Discussion Paper Series, 2002, pp.1-38.

8. Erlicher, L., and Massone L., Human factors in manufacturing: New patterns of cooperation for company governance and the management of change. Human Factors and Ergonomics in Manufacturing, vol. 15, 2005, pp. 403-19.

9. Gershenson, J. K., G. J. Prasad, and Y. Zhang. 2003. Product modularity: Defifinitions and benefifits. Journal of Engineering Design,vol. 14, 2003, pp. 295-313. 